\section{DISTROPHIA ADIPOSOGENITALIS} (FROHLICH'S SYNDROME)

\section{REPORT OF CASE}

J. J. MADIGAN, A.M., M.D.

Neurologist, Georgetown liviversity and Washington Asylum, Wash ington, D. C ; Captain, M. R. C., L. S. Army

FORT THOMAS, KY.

THOMAS VERNER MOORE, PH.D., M.D.

Director, Providence I'sychiatrical Dispensary

$$
\text { WASHINGTON, 1). C. }
$$

History-A boy, aged 10 , was brought to the Providence Psychiatrical Dispensary for general mental backwardness. He was the first horn child. He was followed by a brother born at about the eighth month, who died when 2 weeks old. The next birth was a miscarriage, after which there were no more pregnancies. Venereal disease in the father or mother was denied. The family history of the father was negative. On the mother's side there was a history of various abnormalities. Her father had four brothers and three sisters, two brothers and two sisters being normal, while the other two brothers were described as having deformities of the feet, one of them also having some kind of convulsive seizures; and the other sister went blind at about 30 . The mother of

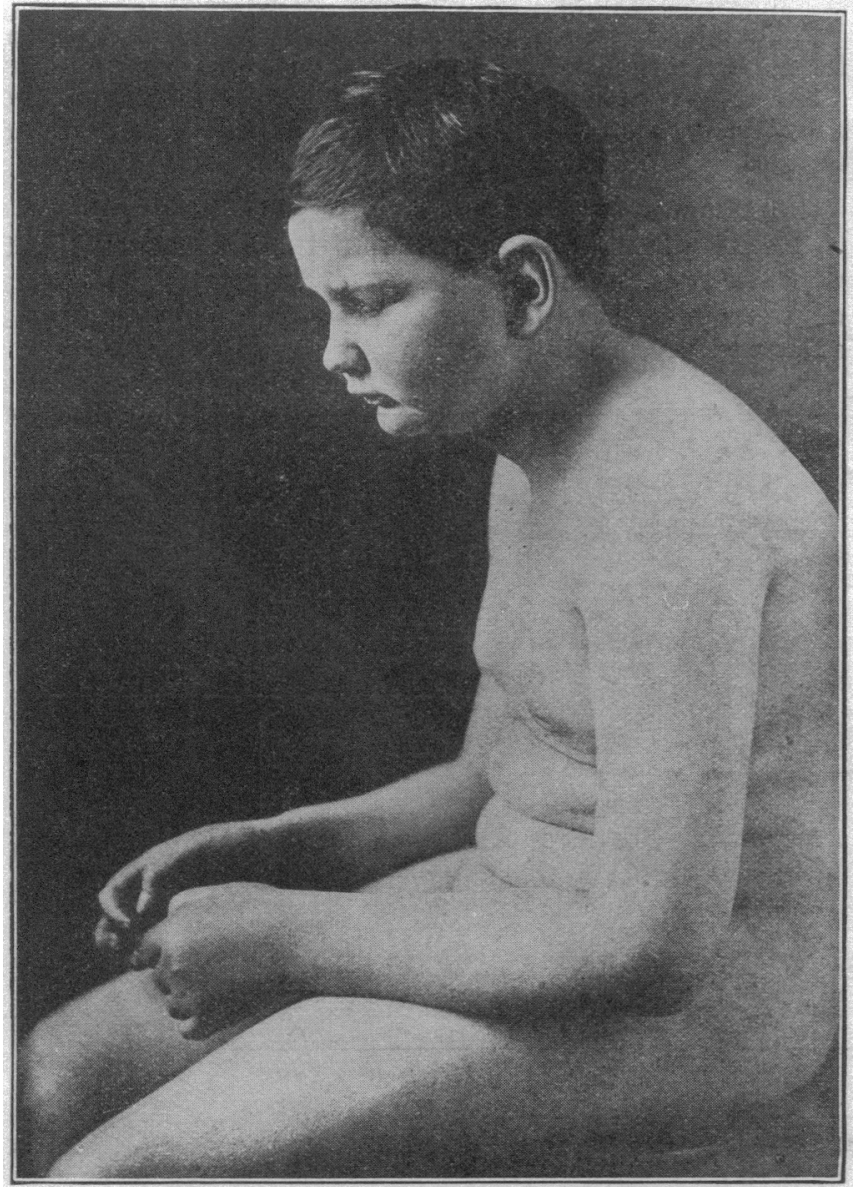

Fig. 1.-Patient, showing the typical adiposity of adiposogenital dystrophy, and the "maxillary prognathism," or, rather, retarded development of the mandible. The upper lip overhangs the lower.

the patient was one of seven normal children. She had one maternal aunt and five maternal uncles, all normal.

In brief, then, we have a family history which is negative excepting the mother's paternal relatives, suggesting a defect in the germ plasm, which might be a mendelian recessive. This is confirmed by the fact that a daughter of the above mentioned aunt married a man whose ancestry is perhaps suspicious (his father died of "creeping paralysis" at 66), and their only child has had from birth an incurable chorea with spasticity of the legs, and though 8 years old, has never spoken.

The patient was a full term child, with normal delivers. His mother does not remember when he cut his first teetl, but he first walked and began talking at about 5 years of age. He did not stop bed wetting until after his ninth birthday. He had "typhoid pneumonia," as the mother describes it, when $21 \%$ years of age; chickenpox when a baby; measles and whooping cough when 9. The present condition dated back apparently to birth. The child was only 3 or 4 months old when the father noticed the jerky movements of the eyes. He never complained of headache or any pain, and there was no history of vomiting that would lead one to suspect intracranial pressure. He har never been able to see, but played about his home in the county with ease, and at first sight one would not notice that he was blind.

Physical Svmptoms. What struck the eye on looking at the patient was the general appearance: the excessive fat for a boy of his age. the feminine form and tapering fingers. When we add to that the fact of his blindness and find that he has a genital

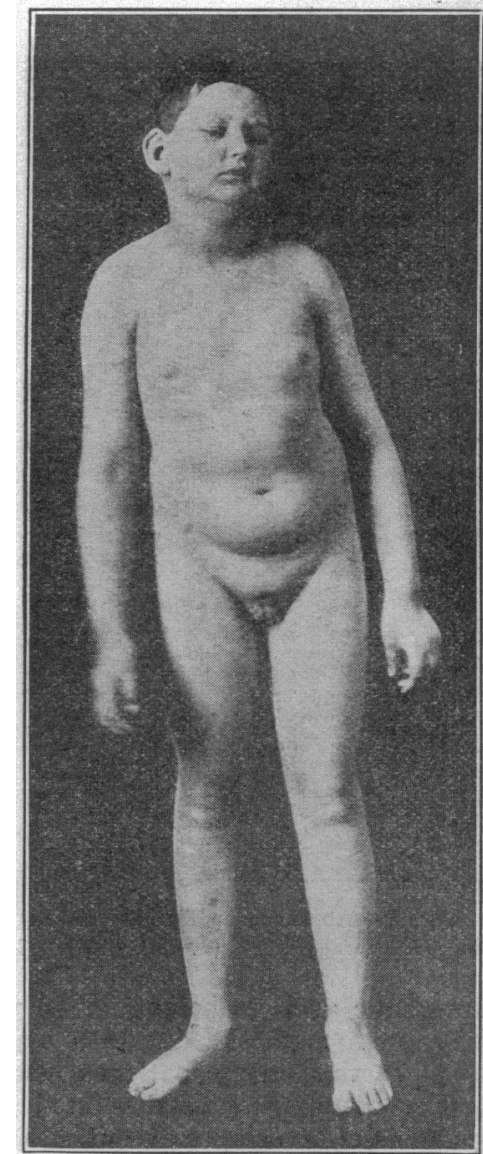

Fig 2-Patient, showing the typical adiposity and the genital dystrophy. aplasia, we have the cardinal symptoms of Fröhlich's syndrome-dystrophia adiposogenitalis.

The symptoms are grouped according to Cushing's scheme:

1. Neighborhood Symptoms: There were no suljective discomforts that could be ascertained. Conversation with the patient, owing to defective speech and reduced mentality, was difficult, and there may have been more subjective symptoms than one would suppose.

There was deformation of the sella turcica. The roentgen ray revealed a flattened sella with the posterior clinoid processes destroyed and the anterior pressed down, suggesting a tumor of the hypophysis originating in the sella and growing up out of it and then pressing down on the clinoid processes.

There were evident visual disturbances. Only perception of light remained. The papillae were much reduced in size and very white. Dr. Henning, an ophthalmologist in Washington, made the following note: "Optic nerve presents a gray white atrophy of nerve head with small vessels. Retina has mottled appearance like a terrazzo floor, with small pigment lumps scattered irregularly and sparsely." There was no exophthalmos, but the eyes were deep sunken in the orbits. There was now a slow lateral nystagmus, which had been much more rapid several months before.

Nasopharyngeal symptoms were noted. Cushing mentions cerelorospinal rhinorrhea as an occasional symptom of pituitary tumor. The mother reported, in this case, a constant somewhat excessive discharge of a clear watery fluid, which of late had somewhat subsided. In the absence of laboratory examirations, one cannot lay much stress on this symptom. 
2. General Pressure Symptoms: The classic pressure symptoms, headache, vomiting and choked disk, are absent. Taking this in connection with the chronic course of the disease, one would expect a benign tumor, which could probably be removed by operative interference.

3. Glandular Manifestations: The boy was $137.2 \mathrm{~cm}$. (4 feet, 6 inches) tall. This means that he was about $6 \mathrm{~cm}$.

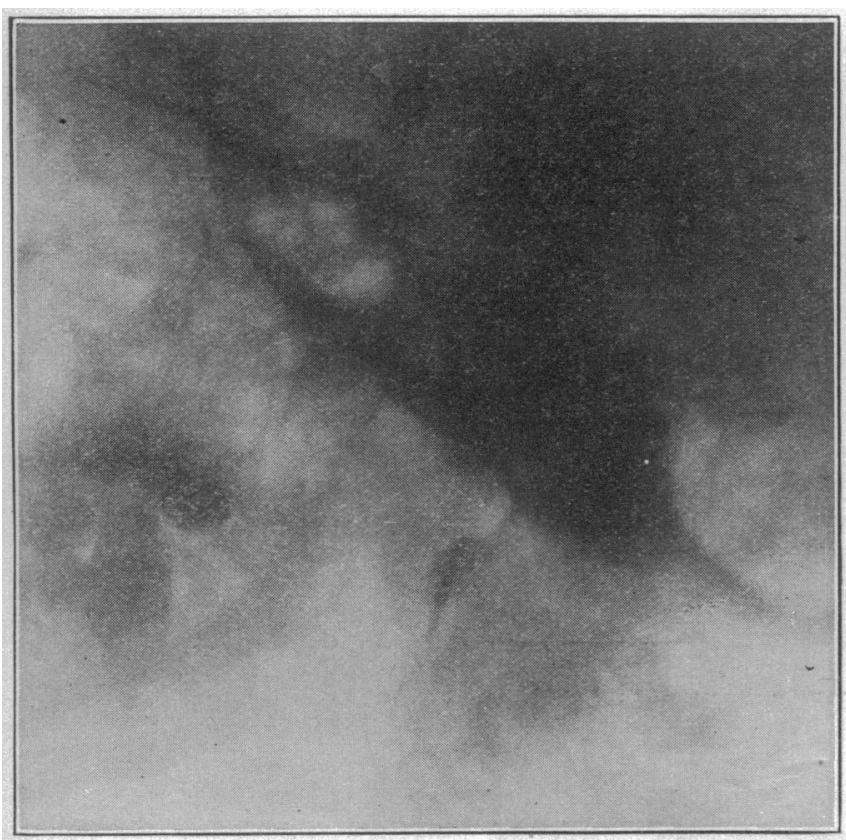

Fig. 3.-Appearance of sella turcica of patient: destruction of posterior clinoid processes, and the anterior process apparently pressed down.

above the average height for 10 year old boys. This excess of growth might be due to a hyperfunction of the pituitary at some time in the patient's history.

The other symptoms pointed to a hypofunction of the gland-the tapering extremities, the marked and typical adiposity. The features were fine, and the skin was smooth, delicate and dry. The hair was abundant on the scalp, but was elsewhere lacking. The condition of the crines, however, was not of such diagnostic importance in a boy of 10 as it would be in an adult.

Another symptom that pointed to hypofunction of the gland was the marillary prognathism as opposed to the mandibular prognathism of acromegaly. If one looked at the patient's maxilla and mandible, it was evident that the condition was not "due to any forward displacement of the sphenoid," as Cushing ${ }^{1}$ supposes, but rather to retarded development of the mandible. The circumference of the head was $50.6 \mathrm{~cm}$. (19\%10 inches)-about $2 \mathrm{~cm}$., therefore, under the normal of 52.6 .

The boy was not in the hospital long enough for a sugar tolerance test.

There was a marked polydipsia. A history of polyuria could not be obtained.

The temperature was normal. The blood pressure was 112 systolic, 70 diastolic.

In testing the mentality of the child, it was found that he could recognize many common objects by touch, repeat three numerals, and place the oljects of the form board in their proper position by trial and error.

4. Symptoms Referable to Other Glands: There was a marked sexual aplasia that must have originated in a prenatal disturbance of growth. The penis was rudimentary, but rather large for clitoris. The mons veneris was very pronounced. The testicles were not descended, and a kind of scrotal membrane covered an "open space." The breasts were definitely developed, with evident mammae.

1. Cushing, Harvey: The Pituitary Body and Its Disorders, Philadelphia, J. B. Lippincott Company, 1912, p. 256.
The thyroid gland was enlarged, palpable, and of rather firm consistency. The pulse was not accelerated; it was about 80 at the time of the examination.

The suprarenals were not seriously involved, although there was a dirty bronzing of the skin.

Over the sternum, just below the clavicle, there was an area of dulness, extending distinctly to the left, which merged into the cardiac dulness below. This might be due to an enlarged thymus.

There was no evidence of the involvement of other glands.

In 1901, Fröhlich"2 described what he termed "a case of tumor of the hypophysis without acromegaly." The cardinal symptoms that he pointed out were $(a)$ adiposity, $(b)$ genital dystrophy, $(c)$ falling out of the hair after the onset of the disease, and $(d)$ atrophy of the optic nerves.

In the later literature, this syndrome became known as dystrophia adiposogenitalis. The condition is associated with a tumor of the hypophysis or one in its neighborhood

In 1908, Bartels ${ }^{3}$ discussed the relation of the changes of the hypophysis to dystrophia adiposogenitalis. He mentions these three theories to explain this relationship:

1. Both tumor and dystrophy are due to inborn, coordinate germinal dispositions (Kcimanlagen).

2. Changes in the hypophysis, due to the tumor, account for the dystrophy.

3. Not the changes in the hypophysis, lut injury of a neighboring center at the base of the brain causes the changes.

Bartels adopts the first of these hypotheses.

The studies of Cushing render it abundantly evident that changes in the pituitary are frequently the cause of the dystrophy. But the cases which produce this evidence have their onset rather late in life.

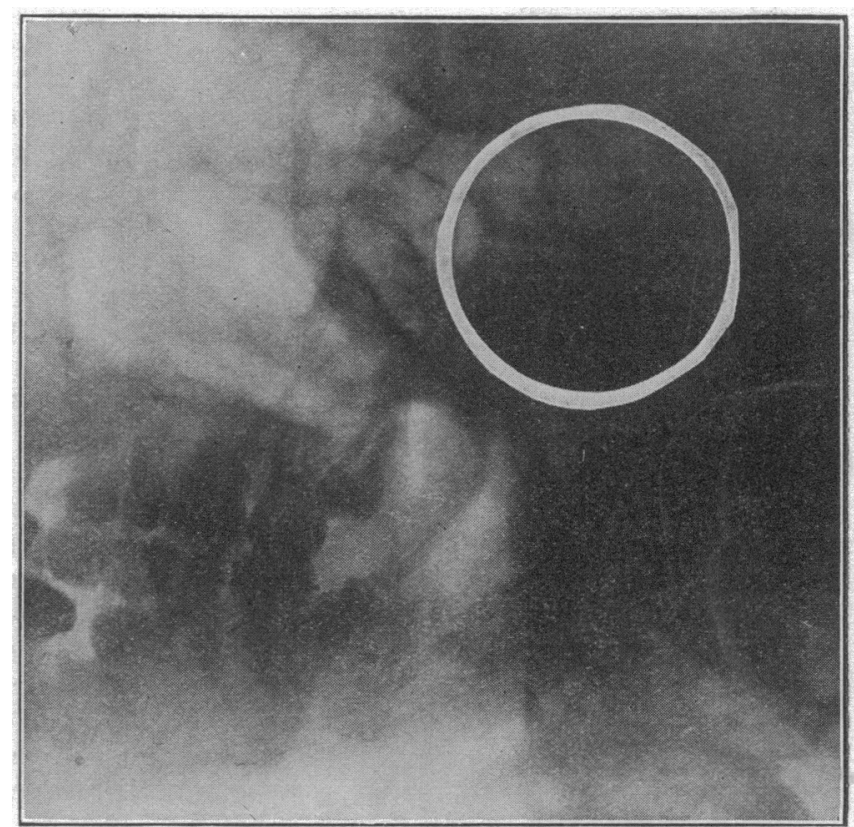

Fig. 4.-Normal sella turcica, with outlines dotted for comparison with Figure 3

There is perhaps room for a small number of cases whose origin is prenatal, and in which a hereditary

2. Fröhlich, Alfred: Ein Fall von Tumor der Hypophysis cerebri ohne Akromegalie, Wien. klin. Rundschau, 1901, 15, 883-886; 906-908 (references to fifty-six articles on the subject).

3. Bartels, M.: Ueber die Beziehungen von Veränderungen der Hypophysengegend zu Misswachstum und Genitalstoörungen (Dystrophia adiposo-genitalis), München. med. Wchnschr., 1908, 55, 201.202. 
factor may be detected. In these, both the tumor and the dystrophy may be due, as Bartels maintains, to an inborn coordinate germinal disposition.

The present case suggests precisely this possibility because:

1. There is a hereditary taint, suggested by the number of deformities in the mother's paternal relatives, and by the appearance of a cerebral defect in one of her paternal relatives who married a man of suspicious ancestry. All this goes to suggest a mendelian recessive.

2. The origin of the case is prenatal. The reasons for this are: (a) the assertion of the parents that the child never saw; $(b)$ the fact that the father noticed the nystagmus when the child was only 3 or 4 months old; $(c)$ the fact that the genital aplasia is such that it must date well back into the prenatal history of the child, and $(d)$ the very small optic disks. ${ }^{4}$

\section{ANTHRAX}

A CASE OF B. ANTHRACIS SEPTICEMIA WITH RECOVERY

ROSCOE R. GRAHAM, M.B. (Tor.)

$$
\text { AND }
$$

HERBERT K. DETWEILER, M.B. (Tor.)

TORONTO, ONT.

Anthrax infection in the human being occurs with considerable rarity; but the instances in which the organisms are demonstrable in the circulating blood are very rare indeed. In this communication we describe in detail a case in which an anthracemia was present, followed by recovery.

The relation of human infection to animal infection has been established for many years. The path of infection lies through the medium of animal products, principally hides, of which those coming from China and Argentina furnish the most prolific source. The sites of the initial lesion in the human being are either cutaneous, pulmonary or intestinal. Of the cutaneous lesions, those arising in the neighborhood of the neck are most serious. In such instances collected ${ }^{1}$ between $1899-1904,40$ per cent. led to a fatal issue. This may be explained by the presence of a very marked and far-reaching edema, which characterizes the fourth stage of clinical anthrax. The proximity of the respiratory passages makes the danger from edema in this area obvious.

The tendency of anthrax in man is to remain localized, but penetration may occur into the blood stream at any time and give rise to a fatal septicemia. ${ }^{1}$ In searching the literature one is impressed with the lack of definite information regarding the results of blood cultures. No statistics of any value are obtainable on this point. All writers, however, seem to be agreed on one point, namely, that a septicemia is to be regarded as leading to a fatal termination in the vast majority of cases. While we have found ${ }^{2}$ in the liter-

4. In addition to the references already given, the following will 4. In addition to the references already given, the follow

one to the rather extensive literature on this syndrome:

Riv. di Patol. nerv., 1914, 19, 513-529 (teports of three cases; a good bibliography).

good

266 ( A

Walta (general article with good biblograt in

Congenital Genital Adiposity (Dystrophia Adiposo-Genitalis), New

York Med. Jour., 1914, 100, 1002-1004.

1. Encyclopaedia Medica, 1915, 1. of Inoculation on the Right Arm; Recovery, West London Med. Jour., $1901,6,129$. ature only one instance of anthracemia followed by recovery, we do not consider it likely that this case is the only one successfully treated, particularly in view of the apparent lack of laboratory investigation in many of the cases reported. It is the usual thing to find the various authors dealing only in generalities; and while we meet such statements as "The majority of anthracemias are fatal," 3 the authors cite no definite cases of recovery.

The course of cutaneous anthrax may be divided into four stages, which are briefly: $:^{1}$

1. The presence of an insignificant wound with no sign or evidence of danger, which may remain as such for two or three days.

2. The appearance of a small pimple with a vesicle filled with a clear or blood-stained brownish fluid containing many bacilli, accompanied by the pricking or itching of the vesicle. This stage may last for from twenty-four to thirty hours.

3. Marked induration of the tissue underlying the vesicle, which has become flattened and has a livid color, marking the beginning of necrosis, which is

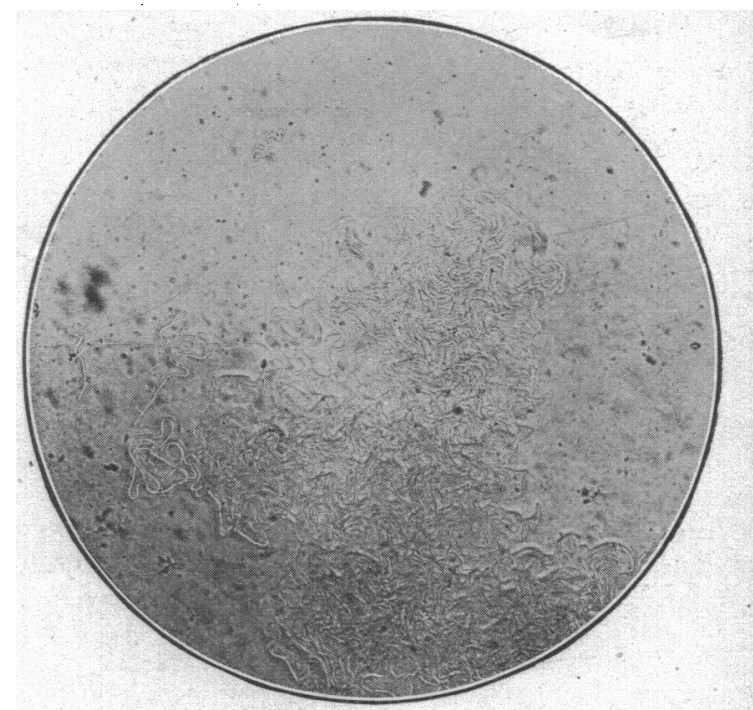

Fig. 1.-Gross picture of growth on agar plate, with typical "doll's surrounded by an edematous ring on which are formed vesicles which may coalesce. In the central dark eschar there are many bacilli. This stage lasts from one to two days.

4. More or less rapid increase of the dark slough along with the edema. The latter may be extensive and very widely spread. Here, because of secondary infection, it is difficult to demonstrate bacilli. The size of this area is variable, and it bears no relation to prognosis.

\section{REPORT OF CASE}

E. M., man, aged 36 , a tanner, admitted to the Toronto General Hospital under Dr. F. N. G. Starr, 8:30 p. m., Nov. 23,1916 , complained of a sore on the left anterior triangle of his neck, with swelling of the left side of the face and neck, extending down over the front of the chest to the junction of the third rib with the sternum.

November 20, he was working more closely than usual with the hides, and in the soaking process he was exposed a good deal to the dust arising from the handling. In the sweating process he often scraped the hides with his thumbnail to determine the progress of the separation of the hair. $\mathrm{He}$ also had a habit, when worried, of stroking his neck

3. Kolmer: Infection, Immunity and Specific Therapy, 1916. 